\title{
RANCANG BANGUN APLIKASI SUPPORTING SALES PENJUALAN RUMAH DI PERUMAHAN BERBASIS ANDROID
}

\author{
${ }^{1}$ Chaerur Rozikin, ${ }^{2}$ Purwantoro \\ ${ }^{1}$ chaerur.rozikin@staff.unsika.ac.id, ${ }^{2}$ purwantoro.masbro@staff.unsika.ac.id \\ Teknik Informatika \\ ${ }^{1,2}$ Universitas Singaperbangsa Karawang, \\ Jl. HS.Ronggo Waluyo, Timur, Karawang, Jawa Barat 41361
}

\begin{abstract}
ABSTRAK
Banyaknya sales yang menawarkan perumahan dalam satu lokasi proyek perumahan akan menjadi keuntungan tersendiri yaitu rumah yang akan dijual lebih cepat laku. Biasanya koordinasi antar sesama sales penjualan rumah menggunakan media whats up. Koordinasi ini diperlukan untuk memetakan dan mencatat secara manual rumah yang sudah dan belum dipesan oleh pembeli kemudian data tersebut disimpan di kantor pemasaran pusat. Permasalahan timbul jika ada dua atau lebih calon pembeli rumah sudah mem-booking dengan blok dan nomor rumah yang sama dengan membayar tanda jadi (booking fee) dan masing masing calon pembeli tersebut dibawa oleh sales penjualan rumah yang berbeda. Sehinga terjadi saling klaim siapa yang dulu memesan rumah. Aplikasi berbasis android yang akan dibuat dalam penelitian ini bertujuan untuk membantu dan mendukung sales dalam memasarkan rumah dengan cara memberikan data dan informasi calon pembeli yang sudah mem- booking, rumah yang sudah ter-booking, dan rumah yang belum terbooking. Sales rumah dapat memasarkan rumah berdasarkan data tersebut dan dapat menghindari terjadinya rumah dengan blok dan nomor yang sama ter-booking oleh lebih dari satu calon pembeli sehingga dapat menghindari konflik saling klaim antar calon pembeli. Aplikasi ini akan digunakan oleh sales rumah dengan meng-install aplikasi tersebut ke smartphone mereka sehingga dapat meng-update data dan informasi rumah yang akan dipasarkan tanpa ada batasan waktu dan wilayah. Aplikasi yang akan dibuat dalam penelitian ini menggunakan metode pengembangan sistem Software Development Life Cycle (SDLC) dengan model prototyping dimana terdapat langkah-langkahnya yaitu Communication, Quick Plan, Modeling Quick Design, Construction of Prototyping, dan Development Delivery and Feedback.
\end{abstract}

Kata kunci :Aplikasi, Marekting, Perumahan

\section{PENDAHULUAN}

Salah satu program unggulan dari pemerintah pusat periode 2014 - 2019 adalah menyediakan serta membangun sejuta perumahan untuk masyarakat yang tergolong dalam kategori Masyarakat Berpehasilan Rendah (MBR) diseluruh wilayah Indonesia. Untuk memperkuat program unggulan pemerintah tersebut, menteri pekerjaan umum dan perumahan rakyat telah menerbitkan aturan kementerian nomor 48/PRT/M/2015. Adanya peraturan menteri ini dan kemudahan lain untuk membantu dalam pembangunan rumah menambah semangat bagi para pengembang untuk membangun perumahan khususnya perumahan yang disubsidi oleh pemerintah.

Semangat pengembang rumah untuk membangun perumahan telah ditunjukan dengan membangun ratusan bahkan sampai ribuan rumah dalam satu komplek perumahan. Pengembang telah memiliki banyak sales rumah untuk membantu mereka dalam melakukan penjualan rumah di perumahan yang mereka sedang bangun. Mulai dari bentuk lahan kosong yang sudah terkavling dengan nomor blok dan no rumah yang sudah ditentukan oleh pengembang kemudian sales/marketing memasarkan perumahan tersebut. Sales dengan sales yang lainnya dalam satu komplek perumahan mencoba untuk memasarkan dan mencari konsumen yang ingin membeli rumah tersebut, ketika dapat konsumen yang ingin membeli rumah biasanya sales meminta konsumen untuk mem- booking rumah tersebut dengan membayar booking fee kemudian sales menandai blok dan no rumah secara manual dan kemudian sales meminta konsumen untuk melengkapi persyaratan administrasi dengan waktu yang telah disepakati.

Selama ini sales memberi tahu blok dan no rumah yang sudah di-booking kepada sales lainnya menggunakan media komunikasi group whats up kemudian mencatatnya secara manual di kantor. Permasalahanya media group whats up memiliki kelemahan yaitu informasi data rumah yang sudah dan belum di-booking tidak ter-update secara otomatis dan cenederung tenggelam informasinya karena tertimpah dengan pesan baru lainnya yang berada di group whats up tersebut. Adanya 
kelemahan dari sisi komunikasi menggunakan media group whats up dan pencatatan manual di kantor tersebut menyebabkan masih sering terjadinya satu rumah dengan blok dan no rumah yang sama di-booking oleh pembeli yang lainnya, sehingga menyebabkan perselisihan antar pelanggan yang mau membeli rumah dengan blok dan no rumah sama dan sudah melakukan booking dengan membayar booking fee, akan tetapi tidak tercatat rapih karena masih menggunakan pencatatan manual. Selain itu data pembeli rumah dan rumah yang sudah ter-booking tidak ter-record dengan baik, hal ini karena media whats up pada dasarnya hanya digunakan sebagai media komunikasi bukan tempat me-record suatu kegiatan tertentu.

Aplikasi android sekarang ini banyak digunakan untuk mendukung kegiatan tertentu sesuai dengan kebutuhan yang diinginkan oleh pengguna. Aplikasi android berkembang pesat karena kemudahannya dalam melakukan penyimpanan, penyajian data dan informasi dengan akurat untuk keperluan yang diinginkan oleh pengguna tanpa adanya batasan waktu dan jarak (wilayah). Pada aplikasi android, waktu dan jarak (wilayah) tidak menjadi masalah karena aplikasi android dapat digunakan pada perangkat bergerak (smartphone) sehingga dapat digunakan dimana dan kapan saja. Pesatnya perkembangan aplikasi android dibuktikan dengan banyaknya penelitian yang berkaitan dengan aplikasi android untuk mendukung dan memudahkan suatu kegiatan atau proses tertentu sesuai dengan keinginan pengguna dari aplikasi tersebut.

Penelitian yang berkaitan dengan aplikasi android untuk mendukung dan memudahkan pengguna aplikasi diantranya yaitu Aplikasi Antar Jemput Laundry Berbasis Web Service pada Platform Android. Pada aplikasi ini pengusaha laundry akan mendapatkan kemudahan seperti data pelanggan dan lokasi tempat tinggal pelanggan ter-record dengan rapih dan data hasil laundry dapat ter-record dengan baik kemudian disisi pelanggan akan dimudahkan dengan tidak perlu lagi datang ke tempat laundry karena cukup dengan aplikasi android maka pegawai laundry akan menjemput dan mengantar pakain pelanggan (Setiyawati et al. 2016). Penelitian tentang kemudahan dalam mencari lokasi pariwisata di Yogyakarta. Pada penelitian ini para wisatawan baik dalam negeri maupun luar negeri yang ingin berwisata di kota Yogyakarta tidak perlu khawatir akan ketidak tahuan lokasi- lokasi yang menarik untuk dikunjungi oleh wisatawan. Dukungan aplikasi android untuk mencari lokasi wisata di kota Yogyakarta akan memudahkan bagi para wisatawan sehingga wisatawan tidak perlu direpotkan dengan bertanya tenatng lokasi wisata karena sudah dilengkapi dengan fitur GPS yang akan memandu wisatawan ke tempat tujuan (Sarawati dan Suhendro, 2016). Penelitian berikutnya tentang pembuatan aplikasi pencatatan service mobil berbasis android. Pada penelitian ini membahas tentang permasalahan service mobil dilakukan di tempat terpisah dari administrasi bengkel sehingga ketika mobil di cek oleh mekanik mengenai kerusakan dan penggantian spare part di bengkel kemudian mekanik mengajukan ke bagian administrasi menunggu persetujuan sehingga mobil yang harusnya bisa langsung di-service harus menunggu beberapa saat sampai mekanik data dan mendapat persetujuan dari bagian administrasi. Penelitian ini memberikan solusi dari permasalahan tersebut yaitu mekanik tidak perlu repot datang ke administrasi cukup membuka aplikasi andorid kemudian mencatat semua keperluan pada aplikasi android sehingga menghemat waktu mekanik dan bisa langsung mengerjakan service mobil tersebut (Dewi dan Pramono, 2015).

Berdasarkan latar belakang diatas penulis ingin melakukan riset tentang "Rancang Bangun Aplikasi Supporting Sales Penjualan Rumah di Perumahan Berbasis Android”. Aplikasi android yang akan dikembangkan menggunakan metode pengembangan sistem Software Development Life Cycle (SDLC) dengan model prototyping dimana terdapat langkah-langkahnya yaitu Communication, Quick Plan, Modeling Quick Design, Construction of Prototyping, dan Development Delivery and Feedback. Aplikasi android yang dikembangkan bertujuan untuk membantu, memudahkan, dan mendukung sales/marketing dalam melakukan pemasaran dan penjualan rumah di perumahan terutama untuk meminimalisir atau meniadakan dua pelanggan atau lebih yang ingin mem-booking rumah dengan blok dan no rumah yang sama sehingga dapat menghindari terjadinya perselisihan antar pelanggan.

\section{METODE PENELITIAN}

Rancang bangun aplikasi supporting sales/marketing penjualan rumah yang akan dikembangan melalui beberapa tahapan pengumpulan data. Pada tahap ini proses pengumpulan data dan informasi yang berkaitan dengan topik riset diperdalam dan didetaikan agar data dan informasi yang didapat valid dan benar benar mendukung dalam riset ini. Beberapa tahap dalam pengumpulan data meliputi studi pustaka, observasi, dan wawancara.

\section{Studi Pustaka}

Pada tahap pengumpulan data dengan cara studi pustaka dilakukan guna untuk memperdalam 
terkait dengan topik bahasan yang pernah dilakukan peneliti yang lain. Pada tahap ini juga akan memperlajari mendalami tentang teknologi smarphone khususnya yang bisa digunakan oleh sistem operasi android.

\section{Observasi}

Observasi merupakan tahapan dimana pada tahap ini akan dilakukan kunjungan langsung dilapangan dan mencari tahu hal-hal yang terkait dengan topik penelitian. Kunjungan yang akan dilakukan yaitu mengunjungi beberapa lokasi perumahan dan kantor pemasaran perumahan untuk mencari tahu permsalahan yang ada dilapangan terkait dengan topik penelitian.

\section{Wawancara}

Pada tahapan wawancara akan dilakukan bersamaan pada saat melakukan observasi dilapangan. Wawancara yang akan dilakukan yaitu kepada pihak pengembang perumahan dan pihak sales/marekting perumahan sebagai end user aplikasi yang akan dikembangakan.

\section{Metode Pengembangan Sistem}

Metode pengembangan sistem pada penelitian ini menggunakan metode pengembangan sistem Software Life Cycle Development (SDLC) dengan model Prototype. Model prototype baik digunakan jika pengembang aplikasi dan pengguna aplikasi masih belum bisa mengidentifikasi kebutuhan-kebutuhan aplikasi yang akan dikembangkan sehingga pengembang aplikasi dan pengguna aplikasi duduk bersama untuk membicarakan kebutuhan-kebutuhan apa saja dalam mengembangkan aplikasi yang akan dibuat sehingga aplikasi yang dibuat sesuai dengan apa yang diinginkan oleh pengguna aplikasi. Model prototype memiliki beberapa tahapan diantaranya Communication, Quick Model, Modeling Quick Design, Construction of Prototyping, dan Development Delivery and Feedback. Tahapan ini dapat dilihat pada Gambar 1 sebagai berikut (ANGON, 2016).

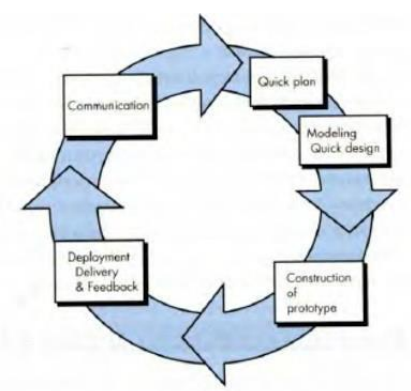

Gambar 1. Tahapan Prototype

\section{Komunikasi (Communication)}

Tahapan komunikasi dilakukan antara pengembang aplikasi dengan pengguna aplikasi. Tahapan ini untuk membicarakan dan mengidentifikasi kebutuhan-kebutuhan yang diperlukan dalam mengembangkan aplikasi dan permasalahan-permasalahan yang ada pada proses pemsaran/penjualan rumah sehingga aplikasi yang dibuat dapat menjawab kebutuhan dan permasalahan pengguna aplikasi. Tujuan dari tahapan ini adalah untuk mendefinisikan semua kebutuhan kebutuhan yang ada dalam aplikasi agar aplikasi yang dibuat sesuai dengan keinginan atau kebutuh pengguna aplikasi. Pada tahap ini yang akan dilakukan adalah observasi dilapangan dan wawancara dengan pihak pengembang perumahan dan sales penjualan rumah. Hasil dari observasi dan wawancara akan dijadikan dasar untuk mengembangkan perangkat lunak.

\section{Perancangan model cepat (Modeling quick Design)}

Setelah selesai melakukan perencaan dalam mengembangkan aplikasi. Tahap berikutnya yaitu membuat rancangan dengan memodelkan hasil perencanaan dalam bentuk dokumentasi program. Dokumentasi program merupakan hasil implementasi dari bentuk perncaan kedalam bentuk dokumen yang dapat di mengerti oleh programmer. Tahapan ini meliputi use case diagram, activity diagram dan lain lain. Dokumentasi program ini akan dibutuhkan oleh programmer untuk diterjemahkan dalam baris code sesuai dengan apa yang telah didokumentasikan.

\section{Pembangunan Prototipe (Construction of Prototyping)}

Pada tahapan ini pengembang aplikasi akan memulai membuat implementasi file dokumentasi program kedalam kode program. Kode program yang akan digunakan untuk pengembangan aplikasi ini adalah dengan menggunakan bahasa pemrograman java, xml dan dengan editor android studio. Pada tahap ini juga dilakukan pengujian dari sebuah kode program agar alur 
logic dari program tersebut sesuai yang telah didokumentasikan.

\section{Pengiriman dan Umpan Balik (Development Delivery and Feedback)}

Setelah selesai tahapan pembangunan kode program selanjutnya adalah menguji seluruh program agar semuanya berfungsi dengan baik dan sesuai dengan kebutuhan pengguna. Pengujian dilakukan dengan langsung mengimplementasikan dalam smartphone android dan kemudian mencobanya langsung. Setelah selesai dilakukan pengujian secara keseluruhan dan berjalan normal maka tahapan selanjutnya adalah mengirimkan aplikasi tersebut untuk dicoba oleh pengguna aplikasi dalam hal ini adalah sales/marketing dan pengembang perumahan.

\section{PEMBAHASAN}

\subsection{Komunikasi (Communication)}

Komunikasi dilakukan untuk memperoleh data dan informasi yang berkaitan dengan pemesanan rumah disuatu perumahan. Komunikasi dilakukan dengan observasi di kantor pemasaran perumahan kemudian melakukan wawancara dengan marketing perumahan dan pelanggan yang akan melakukan proses pembelian rumah dilingkungan perumahan. Proses komunikasi yang dilakukan menghasilkan diantaranya analisis sistem yang berjalan saat ini, analisis sistem yang akan dikembangkan, dan identifikasi kebutuhan hardware dan software sistem.

\section{Analisis Sistem Berjalan}

Proses komunikasi yang telah dilakukan melalui wawancara dengan tim marketing dan pelanggan perumahan akan menghasilkan data dan informasi berupa alur dan prosedur administrasi dalam melakukan pemesanan rumah dilingkungan perumahan. Alur dan prosedur pemesanan rumah dilingkungan perumahaan yang saat ini berjalan terbagi menjadi beberapa proses pertama proses dilakukan pelanggan, kedua proses yang dilakukan tim marketing, dan ketiga proses yang dilakukan staf administrasi Gambar 2.

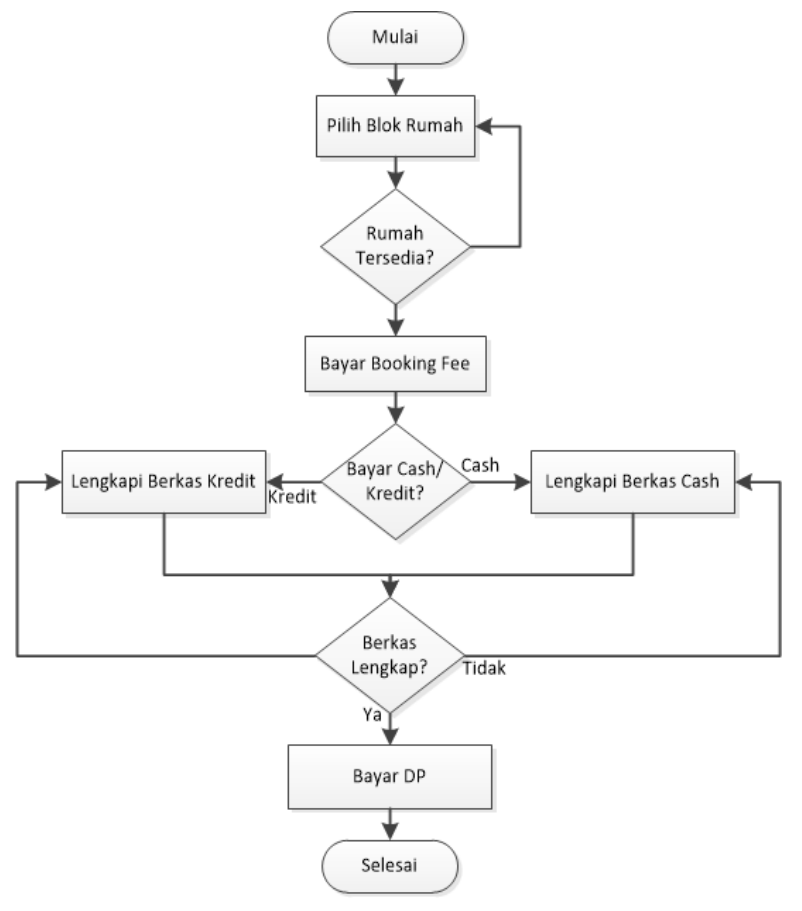

Gambar 2. Alur Pelanggan Memesan Rumah

Marketing akan menawarkan pilihan rumah yang tersedia kepada pelanggan sehingga pelanggan yang sudah mendapatkan penjelasan dari marketing dapat menentukan pilihan rumah yang akan dibeli. Bagi pelanggan yang tidak tertarik dengan rumah yang ditawarkan maka pelanggan akan mencari rumah lain baik masih dilingkungan perumahan tersebut atau di luar lingkungan perumahan. Bagi pelanggan yang minat dan ingin membeli rumah yang ditawarkan oleh marketing maka pelanggan akan membayar booking fee sebagai tanda jadi pembelian rumah kemudian pelanggan akan diberikan pilihan metode pembayaran cash atau kredit oleh marketing 
setelah itu pelanggan akan menerima kwitansi pembayaran booking fee dan dalam waktu 7 hari pelanggan harus melengkapi berkas-berkas yang dibutuhkan untuk proses pembelian rumah. Marketing akan mengumpulkan seluruh berkas pelanggan yang akan membeli rumah kemudian berkas tersebut akan dikirimkan ke pusat administrasi pembelian rumah. Proses dari alur marketing dalam melayani pelanggan dapat dilihat pada Gambar 3.

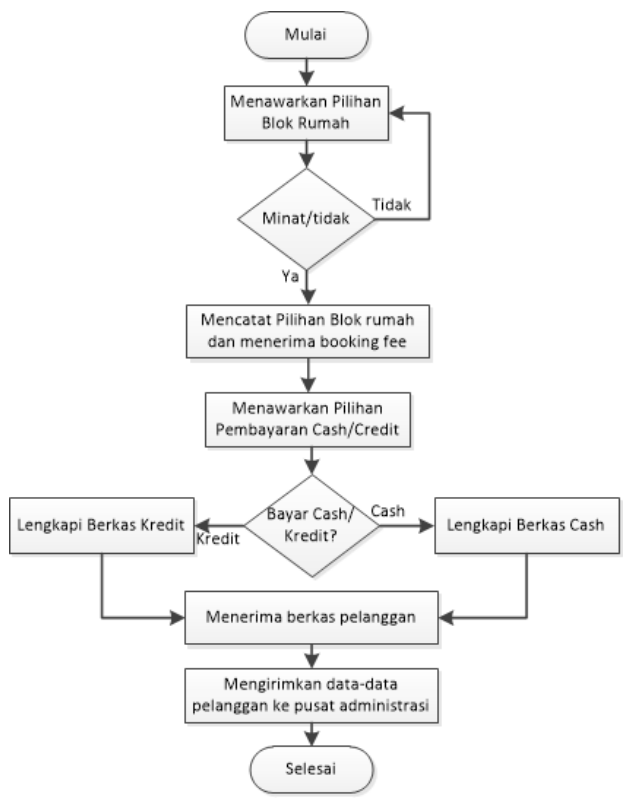

Gambar 3. Alur Marketing

Staff administrasi pusat bertugas untuk mencatat semua berkas-berkas pengajuan kredit dan berkas berkas pembelian rumah secara cash. Staff administrasi berfungsi sebagai pencatat seluruh rumah yang sudah terjual, terpesan, dan rumah yang masih belum terjual. Alur proses staff administrasi dapat dilihat pada gambar 4. Staff administrasi pusat menerima berkas-berkas pelanggan yang melakukan pembelian rumah dari tim marketing kemudian berkas tersebut akan di verfikasi dan di validasi kelengkapannya. Proses verfikasi dan validasi akan memisahkan berkas pembelian rumah secara kredit dan cash selain itu proses ini akan mengecek kelengkapan berkas yang diterimanya. Berkas pembelian rumah yang belum lengkap tim, staff administrasi akan memanggil tim marketing untuk melengkapi berkas-berkas yang dibutuhkan. Berkas pembelian rumah secara kredit dan berkasnya lengkap akan dikirimkan oleh staff administrasi ke bank yang berkerjasama dengan developer. Berkas ini akan diajukan sebagai pengajuan kredit pembelian rumah oleh pelanggan.

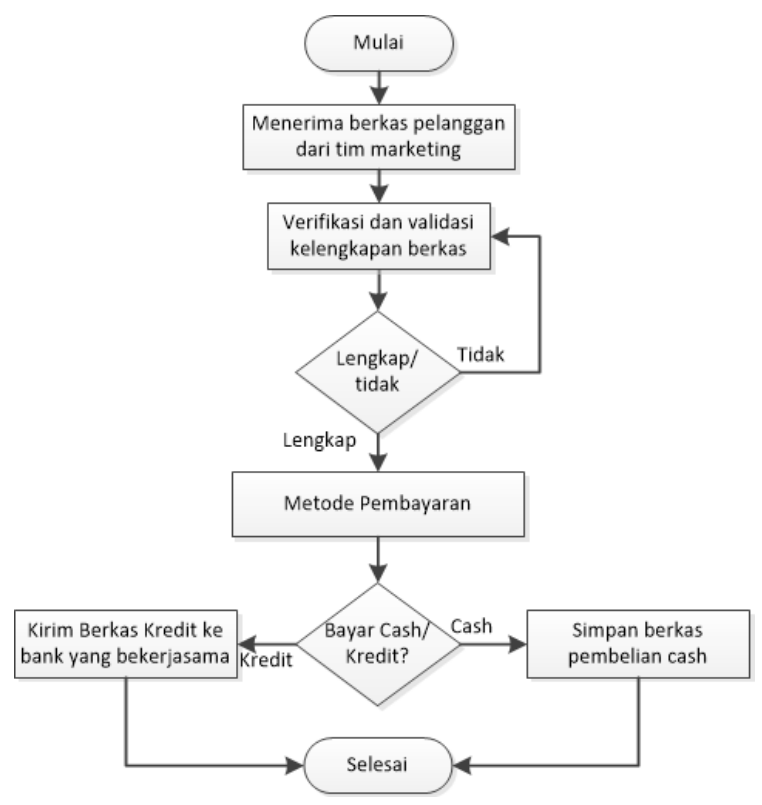




\section{Analisis Sistem Berjalan Yang Akan Diembangkan}

\section{Gambar 4. Alur Staff Administrasi}

Analisis sistem yang akan dikembangkan terdiri dari beberapa bagian yaitu pelanggan, marketing, dan staff administrasi. Analisis sistem pada proses pemesanan dan pembelian rumah yang dilakukan pelangga proses dan prosedurenya sama dengan pada saat menganalisis sistem berjalan pada bagian pelanggan lihat gambar 5. Alur proses disisi marketing yaitu setiap marketing akan membuka aplikasi yang telah dibuat kemudian melihat dan mencari data-data rumah yang sudah terjual, belum terjual, sudah terpesan dan sudah proses pengajuan kredit ke bank. Hal ini dilakukan agar marketing tidak salah dalam menawarkan rumah yaitu rumah yang belum terjual dan bagi rumah yang sudah terjual atau terpesan tidak bisa lagi ditawarkan ke pelanggan. Kemudian marketing akan menawarkan rumah yang belum terjual ke pelanggan dan bagi pelanggan yang minat memesan rumah akan melakukan pembayaran booking fee sebagai tanda jadi kemudian marketing akan mencatat data pelanggan di aplikasi yang dibuat detail alur proses yang dilakukan oleh marketing dapat dilihat pada Gambar 5.

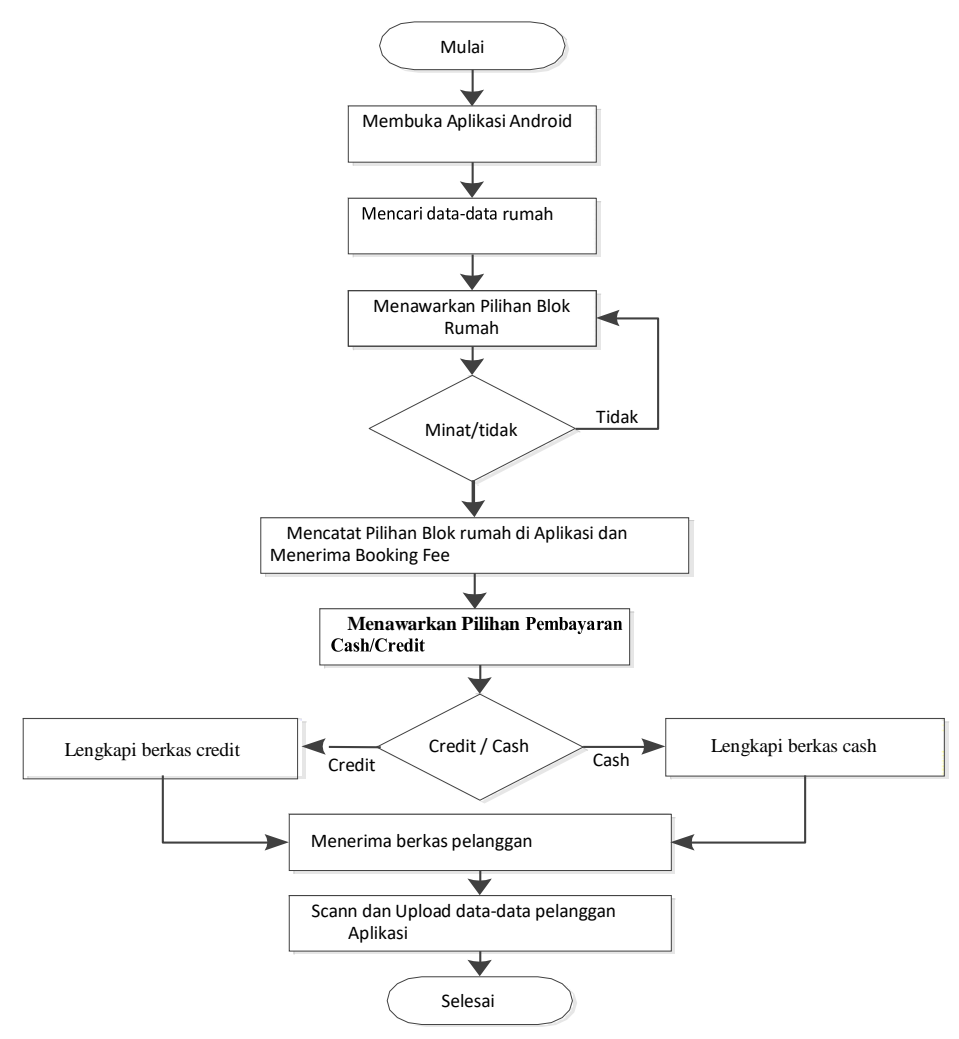

Gambar 5. Alur Marketing Diusulkan

\section{Staff Administrasi}

Analisis proses yang ada pada staff administrasi adalah staff administrasi akan membuka aplikasi kemudian melihat berkas-berkas pelanggan yang sudah diupload oleh tim marketing. Berkas-berkas tersebut akan dilakukan verfikasi dan validasi oleh staff administrasi kemudian berkas yang sudah lengkap akan diberikan tanda centang dan siap untuk diproses selanjutnya yaitu bagi berkas yang pembeliannya secara kredit akan diteruskan ke bank yang telah bekerjasama dan bagi pelanggan yang pembelian secara cash akan di proses oleh tim terkait. Detail alur proses yang ada pada staff administrasi dapat dilihat pada Gambar 6. 


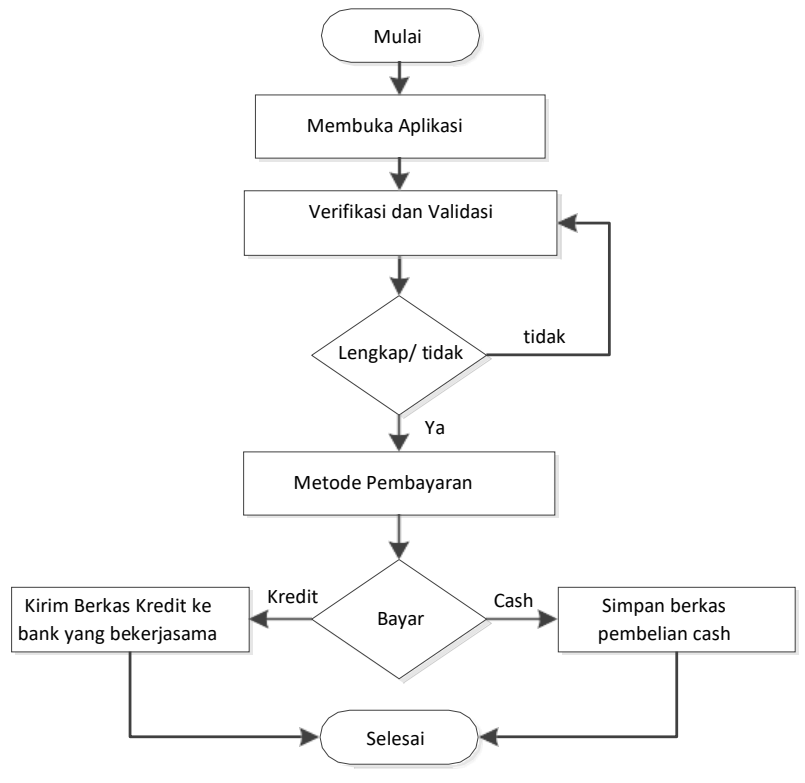

Gambar 6 Alur Staff Administrasi Diusulkan

Pelanggan yang akan memesan dan membeli rumah akan mendatangi kantor pemasaran dan bertemu dengan tim marketing. Pelanggan melihat rumah dan blok rumah yang akan dibeli setelah ada yang cocok maka pelanggan akan membayar booking fee sebagai tanda jadi pembelian rumah. Kemudian pelanggan akan menentukan metode pembelian rumah yaitu cash atau kredit setelah menentukan metode pembayaran pelanggan segera untuk melengkapi berkas-berkas yang dibutuhkan dalam proses pembelian rumah sesuai dengan metode pembayaran cash atau kredit. Alur proses pemeblian rumah dapat dilihat pada Gambar 7 .

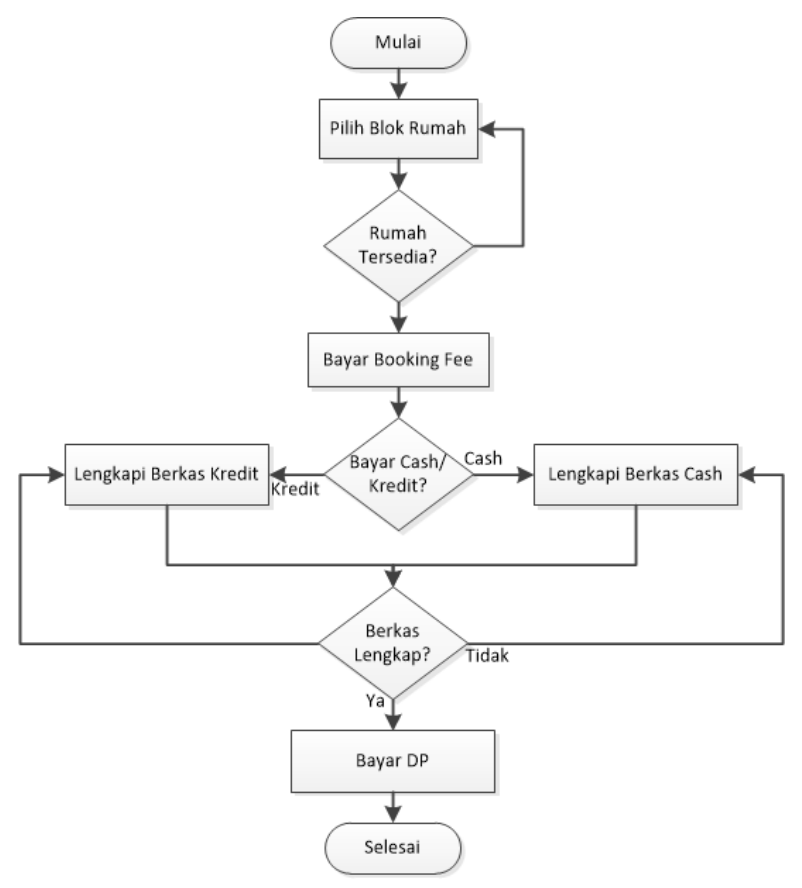

Gambar 7. Alur Pelanggan Memesan Rumah

\section{Identifikasi Kebutuhan Sistem}

Pada tahapan komunikasi ini akan mengidentifikasi kebutuhan sistem untuk mengembangkan aplikasi yang akan dibuat. Identifikasi kebutuhan sistem dilakukan meliputi hardware dan software yang akan digunakan dalam melakukan pengembangan aplikasi berbasis android. 
Tabel 1. Kebutuhan Hardware dan Software

\begin{tabular}{|c|c|}
\hline Hardware & Software \\
\hline Komputer $\quad$ dengan & Komputer $\quad$ dengan \\
\hline $\begin{array}{l}\text { windows, prosesor } 2,7 \\
\text { GHz, Ram } 8 \mathrm{~GB} \text { dan } \\
\text { hardisk } 100 \mathrm{~GB}\end{array}$ & $\begin{array}{l}\text { windows, prosesor } 2,7 \\
\text { GHz, Ram } 8 \mathrm{~GB} \text { dan } \\
\text { hardisk } 100 \mathrm{~GB}\end{array}$ \\
\hline $\begin{array}{l}\text { Smartphone dengan } \\
\text { spesifikasi sistem operasi } \\
\text { android lolipop, Ram } 4 \\
\text { GB, Rom 64 GB }\end{array}$ & $\begin{array}{l}\text { Smartphone dengan } \\
\text { spesifikasi sistem operasi } \\
\text { android lolipop, Ram } 4 \\
\text { GB, Rom 64 GB }\end{array}$ \\
\hline
\end{tabular}

\subsection{Perencanaan Cepat (Quick Plan)}

Tahapan pembuatan perencanaan cepat dilakukan dengan cara memodelkan sistem yang akan dibuat. Pemodelan dalam hal ini akan memodelkan usecase, sequence, aktivty diagram, dan class diagram dari berbagai entitas yang terkait dengan sistem yang akan dikembangkan.

\subsection{Pemodelan Usecase}

Usecase pelanggan menggambarkan interaksi pelanggan terhadap sistem yang akan dikembangkan. Pelanggan bisa melakukan beberapa hal diantaranya pertama melihat informasi data-data rumah yang terjual, tersedia, dan terpesan. Kedua melihat progres pembelian rumah yang telah dilakukan oleh pelanggan. Pelanggan pada sistem yang akan dikembangkan tidak bisa melakukan login ke sistem karena pelanggan hanya bisa melihat informasi dan progres pembelian rumahnya sedangkan untuk berkas syarat administrasi yang diberikan pelanggan akan diproses dan di upload oleh marketing perumahan. Gambar 8 merupakan usecase dari sisi pelanggan.

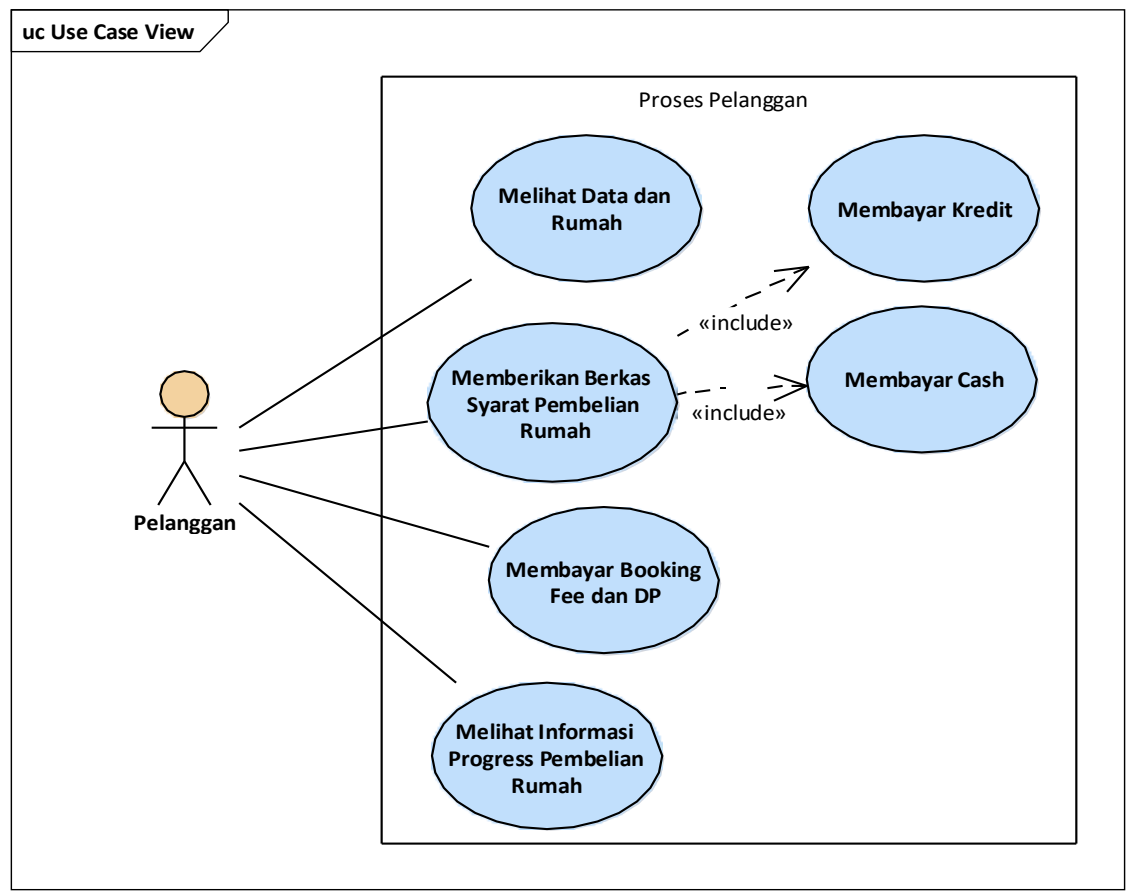

Gambar 8 Usecase Pelanggan

Pemodelan usecase marketing dilakukan untuk mengetahui interaksi marketing terhadap sistem yang akan dikembangkan. Marketing bisa melakukan beberapa hal terhadap sistem diantaranya pertama Marketing bisa melakukan perubahan terrhadap profile yang ada di sistem. Kedua marketing dapat mengelola data pelanggan seperti menambah pelanggan baru, merubah dan menghapus data pelanggan yang sudah tersimpan dalam sistem. Ketiga marketing bisa mengelola data dan informasi rumah yang terjual, tersedia dan terpesan. Keempat marketing bisa mengelola transaksi pembelian rumah dengan melakukan penambahan pelanggan baru kemudian memproses upload berkas administrasi pembelian rumah di sistem. Gambar 9 merupakan usecase dari marketing. 


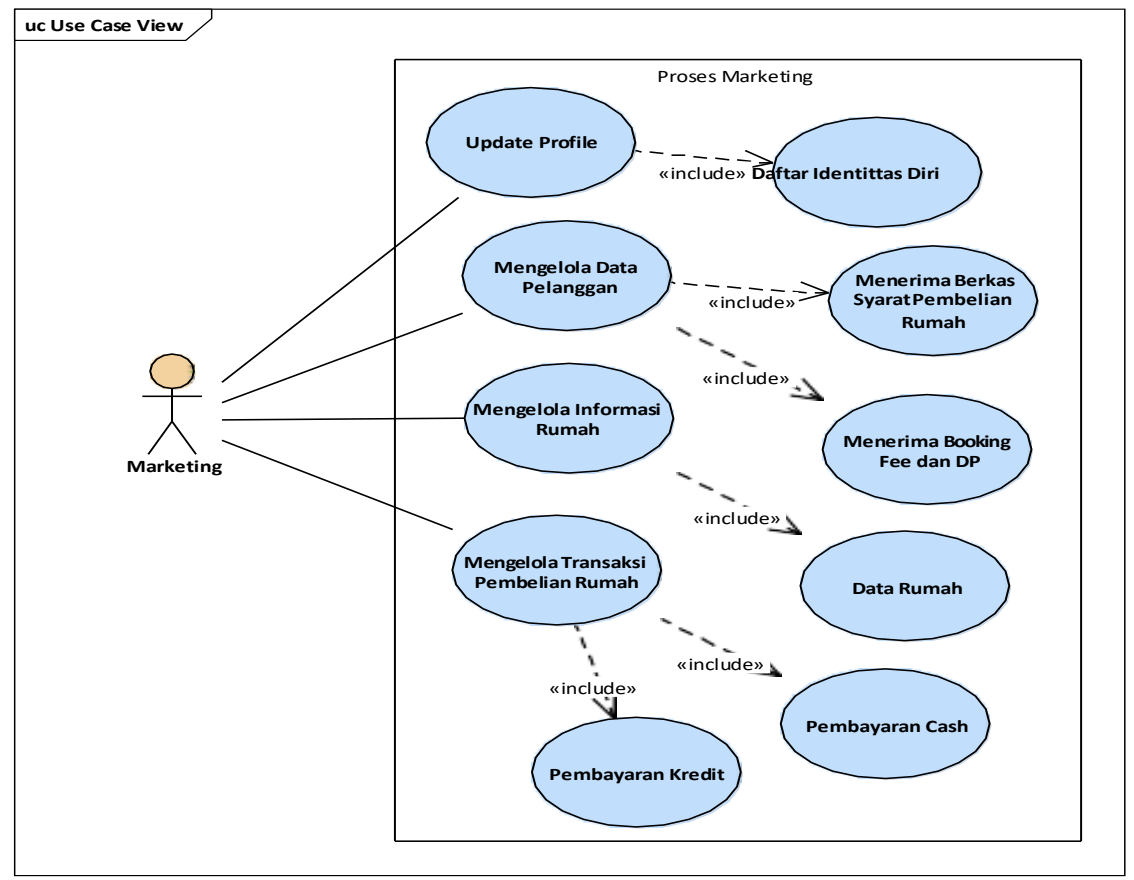

Gambar 9 Usecase Marketing

Pemodelan interaksi staff administrasi terhadap sistem dapat dimodelkan dengan usecase. Staff administrasi merupakan aktor yang akan berinteraksi dengan sistem dan bisa melakukan beberapa hal terhadap sistem diantaranya pertama staff administrasi dapat melakukan perubahan terhadap profile yang ada pada sistem. Kedua staf administrasi proses verifikasi dan validasi terhadap berkas yang sudah diupload oleh marketing. Ketiga staff administrasi bisa melakukan pengelolaan data dan informasi marketing meliputi penambahan, perubahan, penghapusan marketing. Ketiga staff administrasi bisa melakukan pengelolaan data rumah seperti menambah, merubah, dan menghapus data rumah. Detail usecase staff administrasi dapat dilihat pada gambar 10.

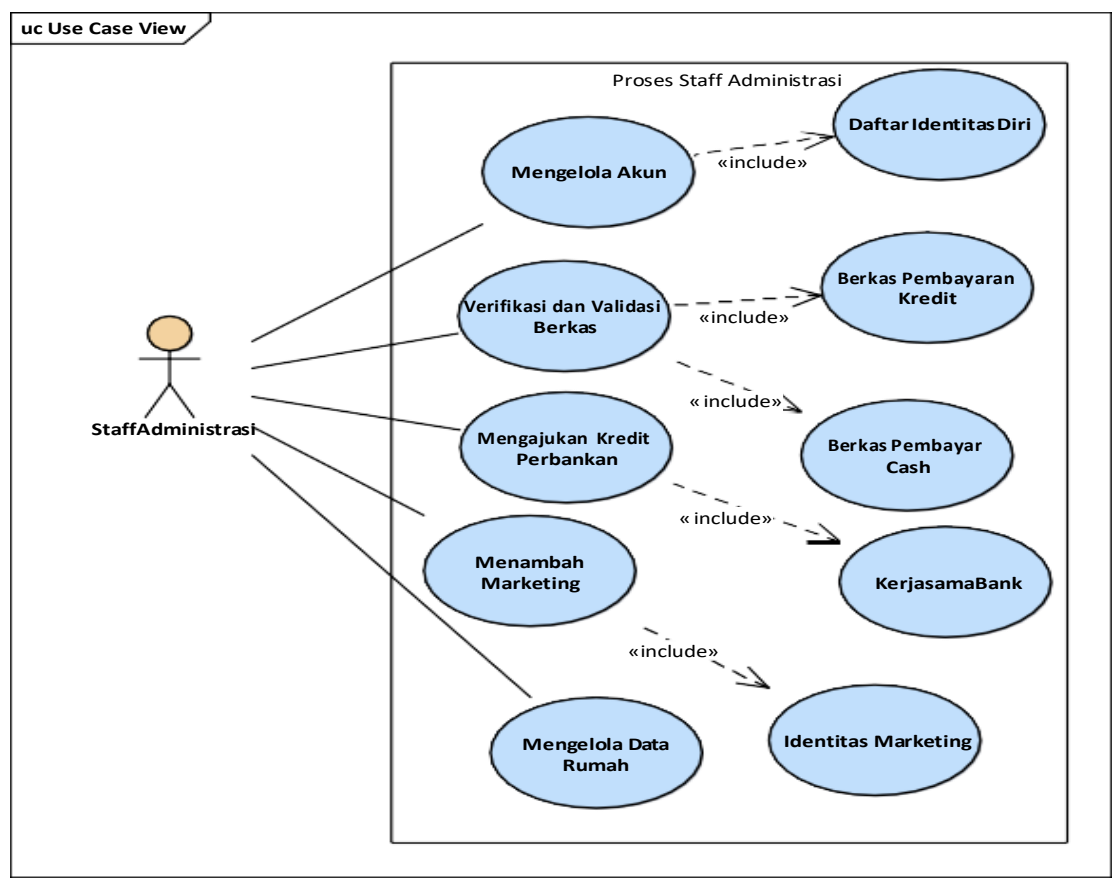

Gambar 10 Usecase Staff Administrasi 


\section{Sequence Diagram}

Squence pelanggan melakukan pencarian informasi rumah di sistem dan setelah rumah yang dicari sesuai maka pelanggan dapat menghubungi marketing untuk melakukan pemesanan rumah. Pelanggan bisa melihat progres pembelian rumah yang sudah dilakukan dengan melalui sistem yang sudah dibuat. Detail sequence dari pelanggan dapat dilihat pada Gambar 11.

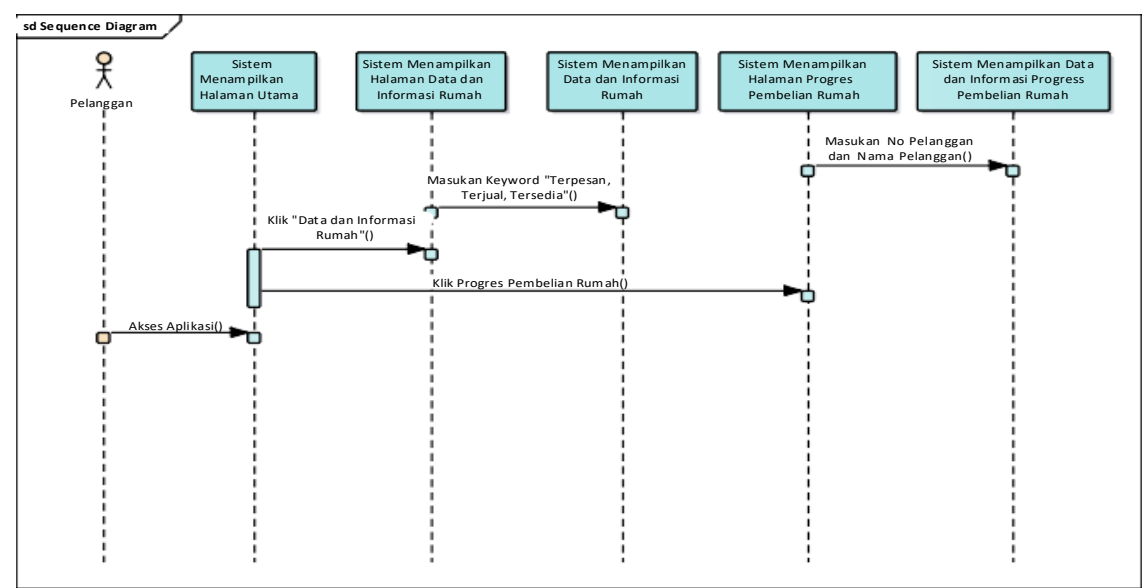

Gambar 11 Sequence Pelanggan

Pemodelan squence marketing terdiri dari beberapa interkasi seperti marketing melakukan login, update profile, update data pelanggan dan proses transaksi pembelian rumah. Detail sequence aktor marketing terhadap sistem seperti terlihat pada Gambar 12.

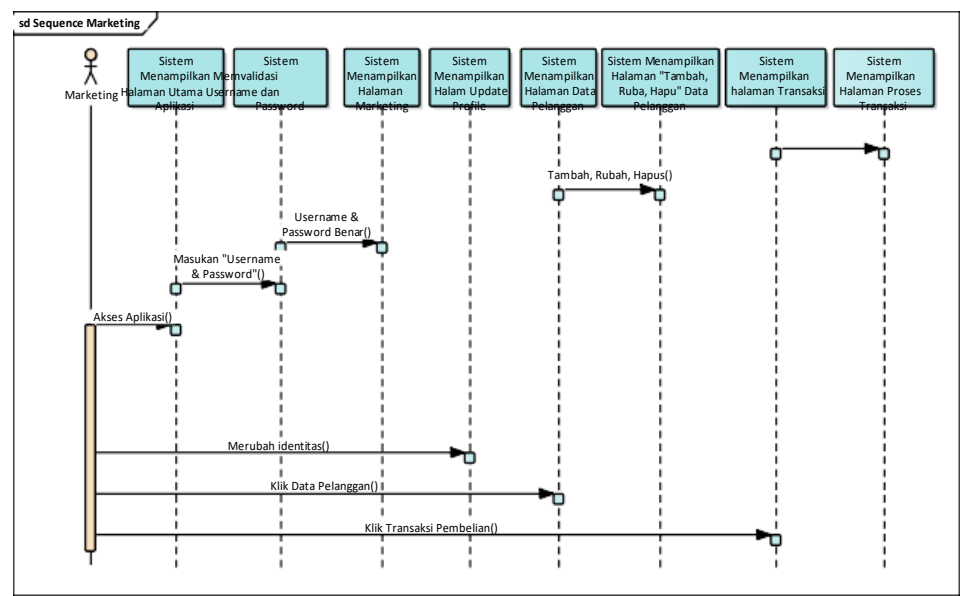

Gambar 12 Sequence Marketing

Sequence staff administrasi meliputi sistem login, merubah profile, menambah data marketing dan menambah data rumah. Detail sequence staff administrasi dapat dilihat pada gamabar 13. 


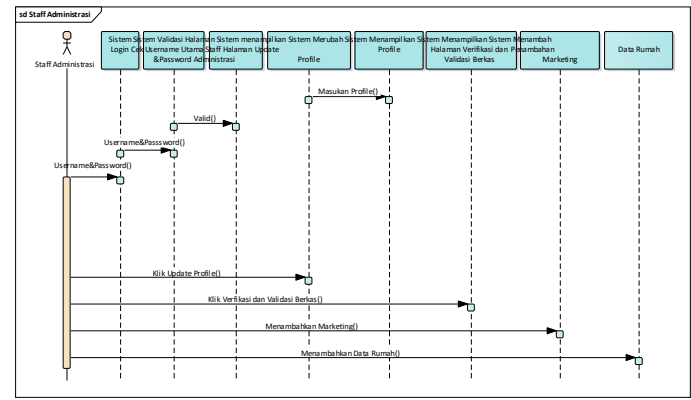

Gambar 13 Sequence Staff Administrasi

\section{Perancangan Model Cepat (Modeling Quick Design)}

Perancangan model cepat dilakukan untuk mengetahui proses rancangan cepat dan dapat dipahami oleh pengguna sebelum diimplementasikan dalam bentuk program aplikasi. Perancangan model cepat merliputi perancangan class diagram, pernacangan database, dan perancangan user interface.

\subsection{Pemodelan Usecase}

Pelanggan bias melakukan beberapa hal diantaranya, pertama melihat informasi data data rumah yang terjual, tersedia, dan terpesan. Kedua melihat progres pembelian rumah yang telah dilakukan oleh pelanggan. Pelanggan pada sistem yang akan dikembangkan tidak bisa melakukan login ke sistem karena pelanggan hanya bisa melihat informasi dan progres pembelian rumahnya sedangkan untuk berkas syarat administrasi yang diberikan pelanggan akan diproses dan di upload oleh marketing perumahan. Gambar 14 merupakan usecase dari sisi pelanggan.

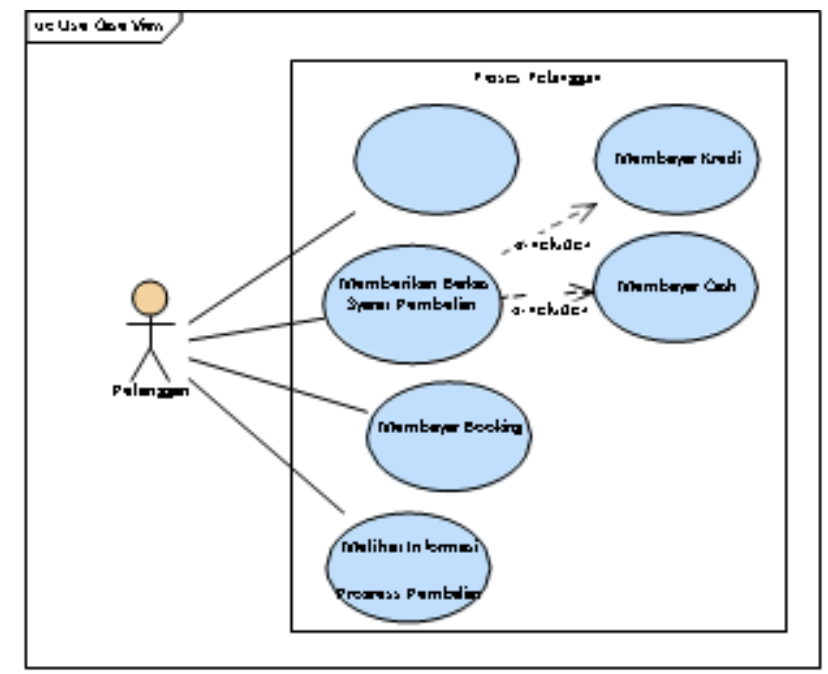

Gambar 14 Usecase Pelanggan

Marketing bisa melakukan beberapa hal terhadap sistem diantaranya pertama Marketing bisa melakukan perubahan terrhadap profile yang ada di sistem. Kedua marketing dapat mengelola data pelanggan seperti menambah pelanggan baru, merubah dan menghapus data pelanggan yang sudah tersimpan dalam sistem. Ketiga marketing bisa mengelola data dan informasi rumah yang terjual, tersedia dan terpesan. Keempat marketing bisa mengelola transaksi pembelian rumah dengan melakukan penambahan pelanggan baru kemudian memproses upload berkas administrasi pembelian rumah di sistem. Gambar 15 merupakan usecase dari marketing. 


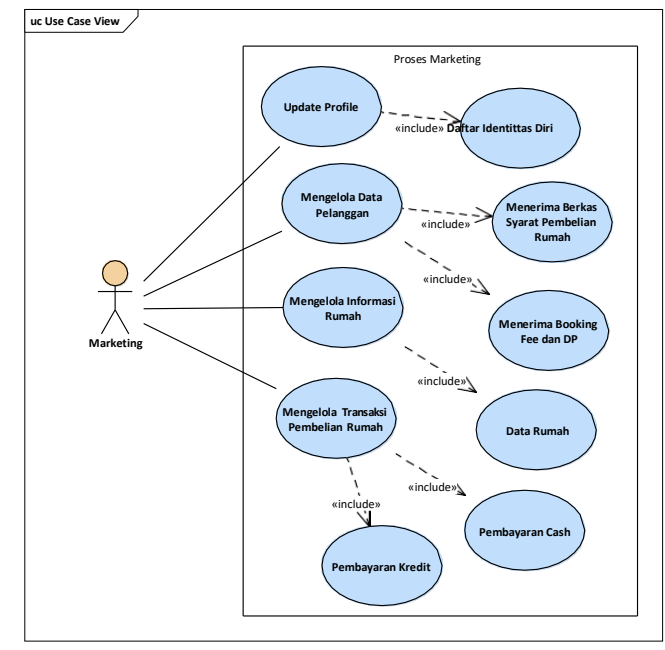

Gambar 15 Usecase Marketing

Pemodelan interaksi staff administrasi terhadap sistem dapat dimodelkan dengan Usecase. Staff administrasi merupakan aktor yang akan berinteraksi dengan sistem dan bisa melakukan beberapa hal terhadap sistem diantaranya pertama staff administrasi dapat melakukan perubahan terhadap profile yang ada pada sistem. Kedua staf administrasi proses verifikasi dan validasi terhadap berkas yang sudah diupload oleh marketing. Ketiga staff administrasi bisa melakukan pengelolaan data dan informasi marketing meliputi penambahan, perubahan, penghapusan marketing. Ketiga staff administrasi bisa melakukan pengelolaan data rumah seperti menambah, merubah, dan menghapus data rumah. Detail usecase staff administrasi dapat dilihat pada gambar 16.

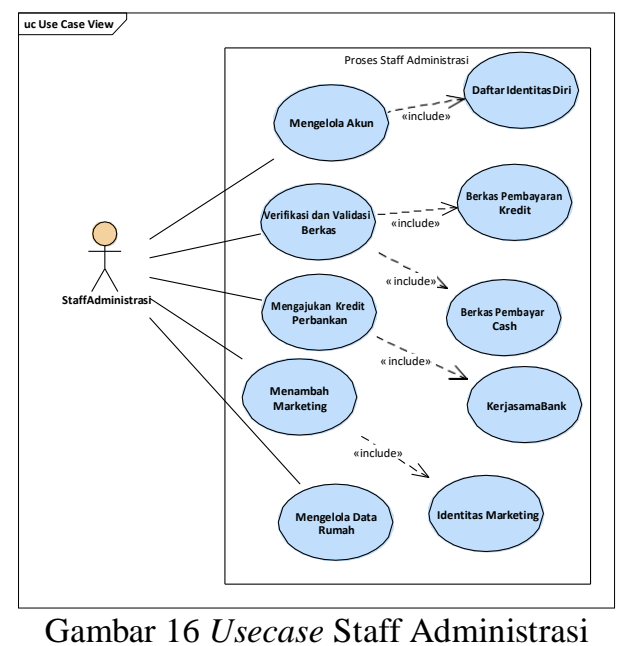

Setelah selesai tahapan pembangunan kode program selanjutnya adalah menguji seluruh program agar semuanya berfungsi dengan baik dan sesuai dengan kebutuhan pengguna. Pengujian dilakukan dengan langsung mengimplementasikan dalam smartphone android dan kemudian mencobanya langsung. Setelah selesai dilakukan pengujian secara keseluruhan dan berjalan normal maka tahapan selanjutnya adalah mengirimkan aplikasi tersebut untuk dicoba oleh pengguna aplikasi dalam hal ini adalah sales/marketing dan pengembang perumahan.

\subsection{Sequence Diagram}

Squence pelanggan melakukan pencarian informasi rumah di sistem dan setelah rumah yang dicari sesuai maka pelanggan dapat menghubungi marketing untuk melakukan pemesanan rumah. Pelanggan bisa melihat progres pembelian rumah yang sudah dilakukan dengan melalui sistem yang sudah dibuat. Detai sequence dari pelanggan dapat dilihat pada Gambar 17. 


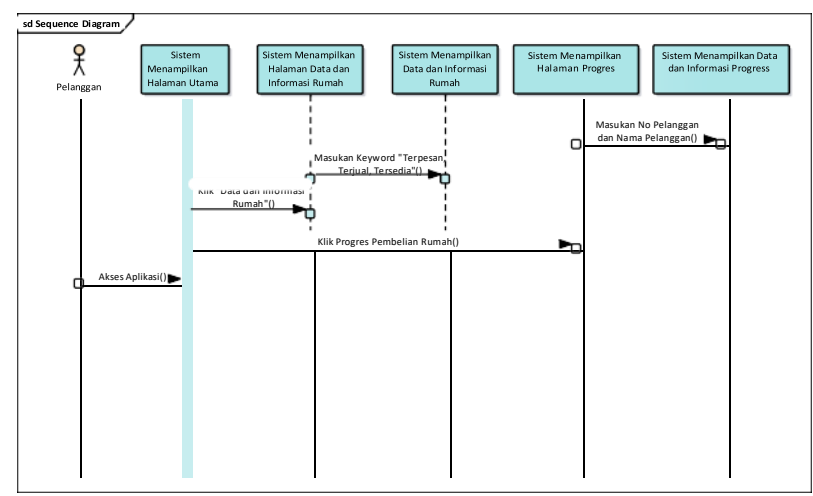

Gambar 17 Sequence Pelanggan

Pemodelan sequence marketing untuk mengetahui aktor marketing dalam melakukan interaksi ke sistem dan respond sistemnya. Pemodelan squence marketing terdiri dari beberapa interkasi seperti marketing melakukan login, update profile, update data pelanggan dan proses transaksi pembelian rumah. Detail sequence aktor marketing terhadap sistem seperti terlihat pada Gambar 18

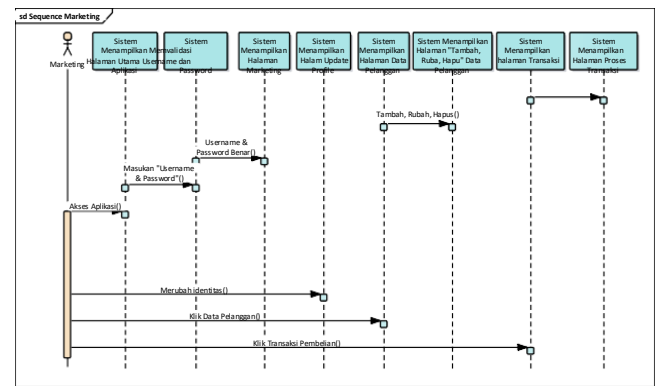

Gambar 18 Sequence Marketing

Pemodelan sequence staff administrasi dilakukan untuk mengetahui urutan yang dilakukan aktor staff administrasi terhadap sistem yang akan dikembangkan. Sequence staff administrasi meliputi sistem login, merubah profile, menambah data marketing dan menambah data rumah. Detail sequence staff administrasi dapat dilihat pada gamabar 19.

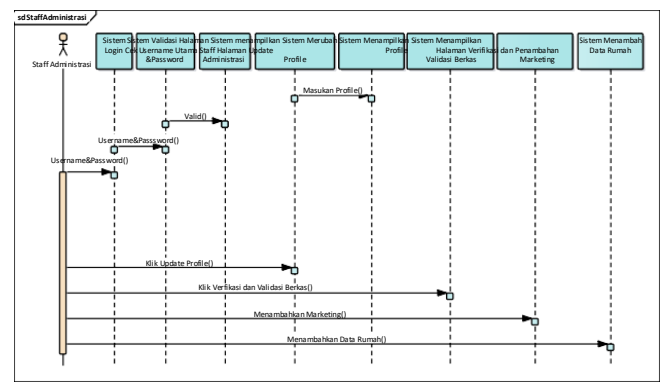

Gambar 19 Sequence Staff Administrasi

\subsection{Perancangan Model Cepat (Modeling Quick Design) Perancangan Class Diagram}

Perancangan class diagram dilakukan untuk mengetahu keterkaitan antar kelas dan hubunganya. Gambar 20 merupakan perancangan class diagram yang telah dibuat. 


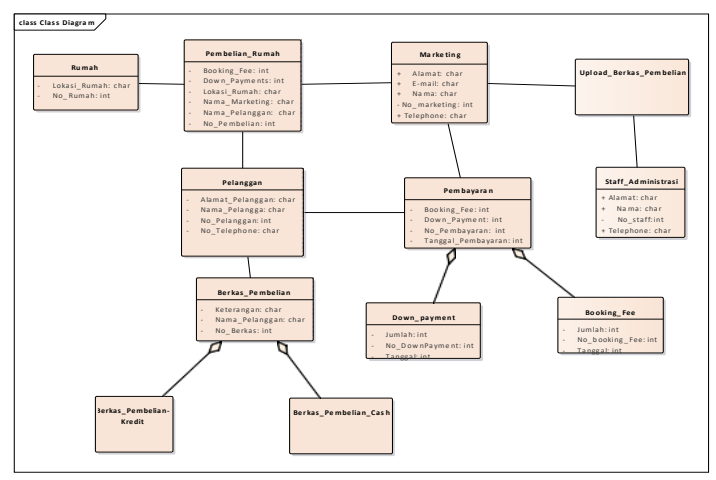

Gambar 20 Perancangan Class Diagram

\subsection{Pembangunan Prototipe (Construction Of Prototyping)}

Pembangunan prototipe dalam penelitian ini merupakan tahapan untuk membuat program aplikasi berbasis android sesuai dengan perancangan yang telah dilakukan. Pembangunan prototipe meliputi staff administrasi, marketing dan pelanngan.

\subsection{Prototipe Pelanggan}

Hasil dari pembuatan prototipe berupa aplikasi berbasis android. Aplikasi yang telah dibuat akan dijalankan di smartphone berbasis android dalam penelitian ini smarphone yang digunakan adalah Doogee Mix dengan spesifikasi Ram 8 Gb dan Rom 64 GB. Gambar 21 merupakan tampilan loading ketika aplikasi dijalankan dan akan menampilkan halaman pelanggan.

\subsection{Prototipe Halaman Marketing}

\section{Prototipe Halaman Login}

Prototipe halaman login lihat gambar 22 dibuat agar marketing dan staff administrasi dapat masuk kedalam sistem. Halaman login ini hanya akan di gunakan untuk staff administrasi dan marketing sedangkan untuk pelanggan tidak sediakan.

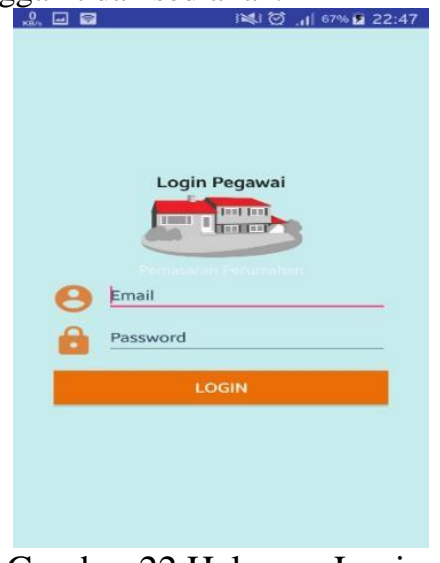

\subsection{Prototipe Marketing}

Gambar 22 Halaman Login.

Pembuatan prototipe marketing dilakukan untuk membuat aplikasi agar marketing bisa melakukan menambah dan merubah data pelanggan, merubah status data rumah dari status tersedia menjadi status terpesan selain itu marketing juga melakukan perubahan profilenya sesuai dengan keinginan mereka. Gambar 23 merupakan hasil dari pembuatan prototipe marketing 


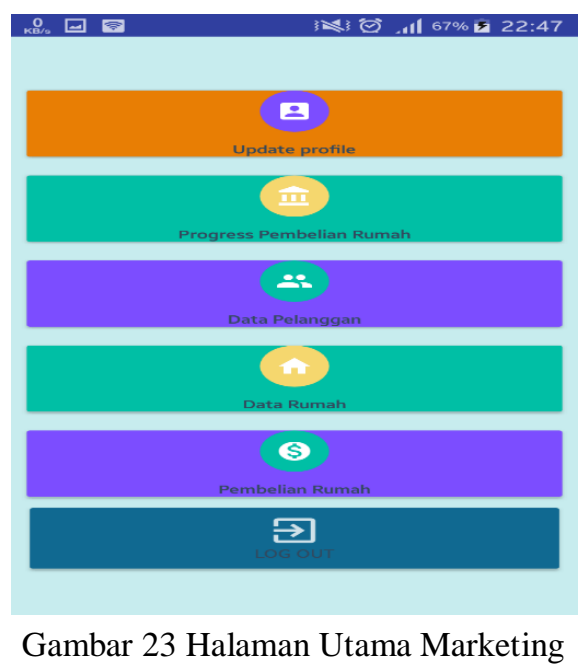

Marketing harus login dulu kemudian sistem akan menampilkan halaman utama marketing. Pada halaman ini marketing bisa melihat dan merubah data profile, progres pembelian rumah, data pelanggan dan pembelian rumah.

\subsection{Prototipe Staff Administrasi}

Prototipe staff administrasi dibuat agar staff administrasi dapat melakukan penambahan marketing, penambahan data rumah, pemberian status rumah yang tersedia, perubahan profile staff administrasi, pengecekan syarat administrasi pembelian kredit dan tunai yang telah diupload oleh marketing, pemberian status progres pembelian rumah. Halaman staff administrasi dapat dilihat setelah staff administrasi melakukan proses login kemudian halaman staff administrasi dapat dilihat pada gambar 24 .

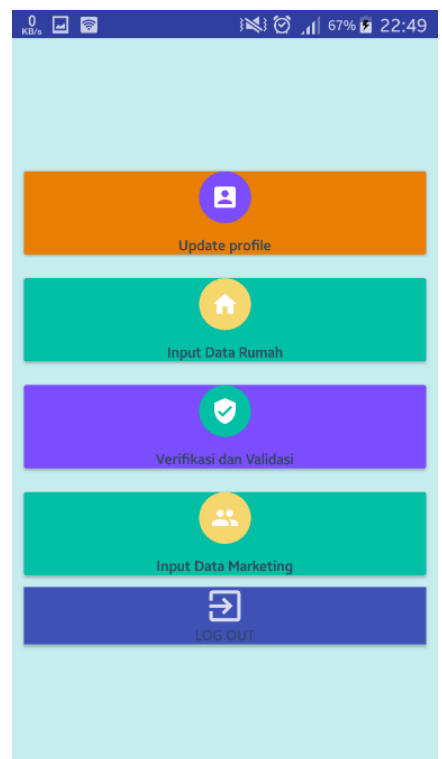

Gambar 24 Halaman Utama Staff Administrasi

Halaman utama staff administrasi seperti gambar diatas ada beberapa item yaitu update profile, input data, verifikasi dan validasi dan input data marketing gambar berikut merupakan halaman dari masing-masing item terebut.

\section{PENUTUP}

4.1 Kesimpulan

Aplikasi yang dikembangkan dalam peneltian ini adalah aplikasi yang digunakan untuk mendukung sales/marketing agar mudah dalam melakukan koordinasi pelengkapan berkas administrasi sebagai syarat pembelian rumah baik kredit maupun cash. Aplikasi yang dikembangkan mampu mencegah terjadinya rumah no dan blok sama dipesan oleh beberapa konsumen. Aplikasi ini juga dapat melakukan cek informasi status rumah, progress pembelian 
rumah dan kekurangan berkas sebgai syarat administrasi dapat di lihat setiap saat.

\subsection{Saran}

Dalam mengembangkan aplikasi ini saran dari penulis agar aplikasi yang akan dikembangkan nantinya dapat melihat dan memonitoring setiap rumah yang terjual, terpesan dan tersedia dan dijadikan sebagai laporan untuk pengusaha perumahan sehingga pengusaha dapat melihat dan mengawasi perkembangan rumah yang dijualnya.

\section{DAFTAR PUSTAKA}

ANDROID STUDIO. 2017. Meet Android Studio. [online] tersedia di https://developer.android.com/studio/intro/index.html?hl=id diakses 5 Juni 2017.

ANGON. Model-Model Pengembangan Perangkat Lunak Beserta Contoh Penerapannya. [online] tersedia di https://www.angon.co.id/news/uncategorized/model-modelpengembangan-perangkat-lunak- beserta-contoh-penerapannya diakses 6 Juni 2017

Ardiansah, Y, Hartanto, A.D. 2015. "Perancangan dan Pembuatan Aplikasi Ready for Battle Futsal Berbasis Android". Jurnal Ilmiah DASI. Vol. 16, No. 1, hal. 63-68.

BISNIS UKM. 2017. Kamu itu Sales atau Marketing Cari Tahu Perbedannya Sekarang. [online] tersedia di http://bisnisukm.com/kamu-itu-sales-atau-marketing-cari-tahuperbedannya-sekarang.html diakses 6 Juni 2017.

Dewi, C dan Pramono, K.M. 2015. "Pembuatan Aplikasi Pencatatan Servis Mobil di PT. Armada International Motor Berbasis Android”. JNTETI. Vol. 4, No. 4.

Deybi, W. E, Sede, Alicia, A. E, Sinsuw, Xaverius, B. N, Najoan. 2015. "Rancang Bangun Aplikasi Pemesanan Tiket Online Kapal Laut Berbasis Android”. E-journal Teknik Informatika, Vol. 6, No. 1.

Kamus Besar Bahasa Indonesia. Rumah. [online]. Tersedia http://kbbi.web.id/rumah diakses 5 Juni 2017. Mulyawan, S dan Budiman, A. 2013. "Perancangan Aplikasi Pembelajaran Tenteang Tindak Pidana Korupsi

Berbasis Mobile". Seminar Nasional Teknologi Informasi dan Komunikasi.

PERMENPU NOMOR 48/PRT/M/2015. 2015. Skema Selisih Angsuran Kredit/Pembiayaan Pemilikan Rumah Bagi Masyarakat Berpenghasilan Rendah dengan Menggunakan Pendapatan Badan Layanan Umum Pusat Pengelolaan Dana Pembiayaan Perumahan. [online]. Tersedia di www.birohukum.pu.go.id/uploads/DPU/2015/PermenPUPR482015.pdf diakses 5 Juni 2017.

PERATURAN PEMERINTAH Nomor 14 Tahun 2016. Tentang Penyelenggaraan Perumahan Dan Kawasan Permukiman. [online] tersedia di diakses 6 Juni 2017.

Rahman T, Kurniawan D. 2017. "Perancangan Pedometer Berbasis Sensor Accelorometer Android". Jurnal Ilmu Pengetahuan dan Teknologi Komputer. Vol. 2, No. 2.

Saraswati NM, Suhendro B. 2015. "Panduan Lokasi dan Akomodasi Wisata Berbasis Android di Yogyakarta".

Teknoin. Vol. 22, No. 4, Hal. 287-295.

Setiyawati YD, Isnanto RR, Martono KT. 2016. "Pembuatan Aplikasi Antar Jemputa Laundry Berbasis Web Service pada Platform Android". Jurnal Teknologi dan Sistem Komputer. Vol. 4, No. 1.

SQLITE. About Sqlite. [online] tersedia di https://www.sqlite.org/about.html diakses 5 Juni 2017. 